\title{
Pobreza, crecimiento y distribución del ingreso en El Salvador durante la década de los noventa
}

\section{Introducción}

Este trabajo presenta un estudio temporal de la magnitud de la pobreza y la distribución del ingreso, en el entendido de que ambos aspectos están profundamente asociados a la evolución de las condiciones de vida en el país. Tanto la distribución del ingreso como los niveles de pobreza han registrado modificaciones en esta década, debido principalmente al patrón de crecimiento predominante que se fundamenta en el flujo de las remesas familiares y la creciente participación del sector informal en la generación de ocupación.

La idea que se sostiene a lo largo del trabajo es la necesidad de un entorno de crecimiento favorable para una estrategia eficaz de combate a la pobreza, que esté acompañado de una política social activa orientada a promover la participación de los sectores de menores recursos en los frutos de dicho crecimiento y a la protección de los grupos más vulnerables. Además, se considera que el crecimiento económico debe fundamentarse en las actividades productivas y en los sectores donde trabajan los pobres para que mejore las condiciones de vida y que dicho crecimiento sea estable y sostenido.

El estudio está dividido en cinco secciones, que están organizadas de la siguiente manera:

- En la primera sección, se analiza la relación entre crecimiento, pobreza y distribución. Al final del apartado, se presentan como elementos esenciales de una estrategia eficaz de combate a la pobreza, un crecimiento estable y sostenido y una distribución más equitativa del ingreso.

- El patrón de crecimiento en los noventa es estudiado en la segunda sección. Dentro de sus principales características, se encuentran el incremento de los flujos extemos, el proceso de terciarización y el sesgo hacia lo urbano. 
- La tercera parte recoge el análisis de la distribución del ingreso, haciendo énfasis en las remesas y el sector informal de la economía como principal determinante de la mejora en la participación de los estratos más bajos en el ingreso total.

- En la cuarta sección, se presenta la evolución de la pobreza y su estrecha vinculación tanto con el dinamismo de la economía como con la migración del campo a la ciudad. Además, se estima el gasto social necesario para cerrar la brecha de la pobreza y la pobreza extrema, demostrándose que con el uso eficiente de los recursos disponibles es posible erradicar la indigencia.

- En la última sección, se establecen los lineamientos de política económica para el combate a la pobreza y la búsqueda de la equidad subrayando la necesidad de fomentar el desarrollo de las actividades donde laboran los pobres y la importancia de la inversión en capital humano como estrategia de eliminación de la pobreza.

\section{Crecimiento, pobreza y distribución del ingreso}

Algunos analistas de la pobreza tales como, Altamir (1995), Beccaria (1992), Lustig (1995), Morley (1995) y Psacharopoulos (1995) llegaron a la conclusión general que la pobreza y la inequidad están estrechamente relacionadas al ciclo económico, aumentando durante los periodos de recesión y disminuyendo durante la recuperación. Por lo que se sostiene que la pobreza y la desigualdad no pueden reducirse sin el crecimiento económico. Sin embargo, la evidencia empírica no es tan concluyente en cuanto al efecto del crecimiento sobre la desigualdad. Ravallion y Chen (1997), utilizando datos de encuestas de hogares para 42 países, encontraron que el crecimiento económico reduce la pobreza, no así la inequidad.

Otros estudios, como los modelos desarrollados por Persson y Tabellini (1994), confirman que la inequidad afecta negativamente al crecimiento económico. Los países con una distribución del ingreso más igualitaria tienden a mostrar una tasa más alta de crecimiento per cápita. Larraín y Vergara (1997) sostienen que la desigualdad en la distribución retarda el proceso de crecimiento porque la inequidad lleva consigo conflictos sociales que incrementan la inestabilidad y tienen un efecto negativo sobre la inversión.

El crecimiento económico es una condición necesaria pero no suficiente para combatir la pobreza. Existen dimensiones de la pobreza que no serán resueltas en un futuro cercano mediante el crecimiento económico, por lo que se requiere una política social activa que ataque las causas de la pobreza y aumente las oportunidades de los pobres para participar y beneficiarse de dicho crecimiento.

Sin embargo, el éxito de dicha política social está condicionado por un entorno de crecimiento económico estable y sostenido. Existe suficiente evidencia empírica que cualquier factor que reduzca la tasa de crecimiento del ingreso per cápita o que cause una recesión perjudica a los pobres. Este argumento se basa 
en el hecho de que los pobres sufren más las consecuencias de una recesión que otros grupos, ya que ningún programa social de emergencia o política social especialmente diseñada para aliviar la pobreza puede compensar completamente el efecto que tiene en los pobres la recesión económica.

Al nivel teórico, se establece que el crecimiento económico puede aliviar la pobreza a través de la creación de empleo productivo y del impacto favorable que suele tener en las remuneraciones de los trabajadores con menores ingresos. Además, se sostiene que el crecimiento ampliará los recursos fiscales que pueden ser invertidos en los sectores sociales o utilizados para financiar programas y proyectos para combatir la pobreza de modo directo.

Por lo tanto, existe un cierto consenso sobre la existencia de una relación positiva entre la tasa de crecimiento del ingreso real per cápita y la tasa media anual de disminución de la pobreza. Sin embargo, la divergencia de opiniones se genera en torno a la importancia o no del estilo de crecimiento. Se pueden identificar dos grandes líneas de pensamiento:

- El crecimiento por filtración que sostiene que cualquier tipo de crecimiento favorecerá a los pobres. Se considera que un alto crecimiento del PIB elevaría automáticamente los niveles de vida de los pobres mediante el mecanismo de rebalse. Sin embargo, el crecimiento por filtración se vería acompañado por un aumento de la desigualdad. Ésta última reduce el nivel de educación que muchas familias pueden costear para sus hijos por la sencilla razón de que son demasiado pobres, lo que crea un círculo vicioso en el que cuánto más desigual es la distribución del ingreso en un país tanto menos puede reducir éste el nivel de pobreza. Finalmente, la desigualdad fomenta la violencia y la inestabilidad política. Estas circunstancias desincentivan la inversión y reducen la tasa de crecimiento de la economía.

- El crecimiento liderado por los sectores donde trabajan los pobres. Los defensores de esta postura sostienen que el estilo de crecimiento que tendrá impacto sobre la pobreza es la estrategia de crecimiento que potencia el aparato productivo de la economía y que maximice los beneficios de los pobres. Esta estrategia debe tener como objetivo último el aumento de las oportunidades de ingresos obligando a que el crecimiento sea liderado por los sectores en que trabajan los pobres'.

El análisis anterior permite identificar los elementos esenciales que debe de poseer una estrategia eficaz de combate de la pobreza:

- El crecimiento económico debe de ser estable y sostenido, y además debe ser complementado con una política social activa que ataque directamente las dimensiones que no pueden ser resueltas por el crecimiento.

- No cualquier estilo de crecimiento puede reducir la pobreza, éste debe orientarse a aumentar las oportunidades de ingresos para los pobres, para lo cual 
se hace necesario un crecimiento basado en las actividades donde opera la población de menores recursos.

- Para ser estable y sostenible, el crecimiento debe fundamentarse en actividades productivas.

- Una mejora en la distribución del ingreso es fundamental para que los beneficios del crecimiento lleguen a los pobres. Si se mantiene sin cambios la distribución del ingreso, el ritmo de reducción de la pobreza podría ser muy lento incluso con un crecimiento sostenido.

2. Principales características del patrón de crecimiento económico en los noventa

\subsection{Recuperación económica}

Durante los años de posguerra, el país ha presentado un entorno macroeconómico relativamente estable posibilitando que la economía creciera a tasas positivas superiores a la tasa de crecimiento de la población. En el período 1990-1998, el producto interno bruto (PIB) real creció a una tasa promedio anual de 5.1 por ciento, después de experimentar una tasa negativa de 2.2 por ciento anual para 1979-1989.

\section{Gráfico 1}

Crecimiento del producto interno bruto a precios de 1990 período 1970- 1998

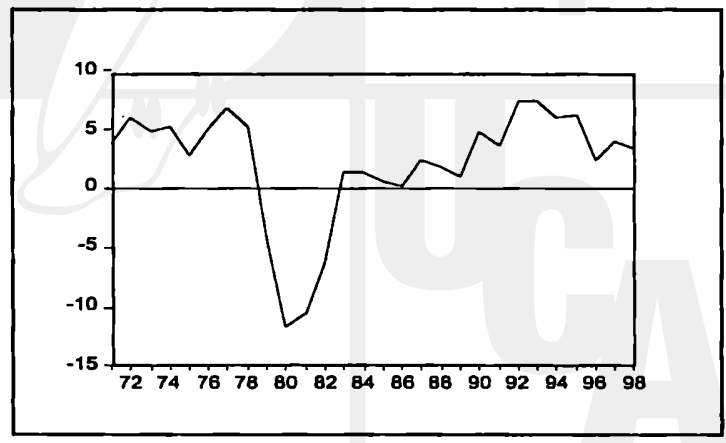

Fuente: revistas del Banco Central de Reserva de varios años.

Sin embargo, el crecimiento en los noventa no ha sido uniforme. Durante el período 1990-1995, el PIB real creció a tasas elevadas, en promedio 5.9 por ciento. A partir de 1996, hay una desaceleración de la actividad productiva dando lugar a un crecimiento promedio del producto para este período de 3.4 por ciento. 
La recuperación económica de los noventa ha estado sustentada en un proceso de recomposición sectorial del aparato productivo y en la consolidación de las remesas enviadas por los salvadoreños residentes en el exterior como la fuente principal de divisas.

\subsection{Economía sustentada por las remesas}

La migración internacional ha tenido extraordinaria importancia para El Salvador en las últimas dos décadas. Entre 1950 y 1970, el saldo neto migratorio internacional era de aproximadamente dos por mil habitantes. Este saldo neto subió a 8 por mil en la segunda mitad de los ochenta, para volver a niveles históricos en los noventa ${ }^{2}$. Como resultado de este saldo migratorio continuo, cerca de un 15 por ciento de hogares salvadoreños reciben remesas desde el exterior (ver anexo 1). Teniendo en cuenta que la mayoría de estos hogares se encuentran en los estratos bajos de la población, se puede afirmar que estos recursos extemos son uno de los principales factores que han contribuido a mejorar la distribución del ingreso y a reducir los niveles de pobreza en el país.

Las remesas se han estabilizado en flujos alrededor de 1157 millones de dólares anuales en la segunda mitad de la década de los noventa, aproximadamente un 11 por ciento del producto interno bruto. Estos flujos constantes de remesas se han traducido en aumentos del gasto interno, tanto en bienes comerciables como no comerciables. El mayor gasto en bienes comerciables resulta en un aumento de las importaciones y un mayor déficit comercial financiado con las transferencias (74 por ciento del déficit en 1995-1998). En cambio, el mayor gasto en bienes no comerciables resulta en un aumento de su precio relativo provocando una apreciación real del tipo de cambio. Esta apreciación real penaliza de modo especial a la agricultura.

\section{Cuadro 1}

Importancia macroeconómica de las remesas

Décadas de los ochenta y los noventa

(En millones de dólares y porcentajes)

\begin{tabular}{lccccc}
\hline Años & Remesas & $\begin{array}{c}\text { Remesas/ } \\
\text { Exporta- } \\
\text { ciones }\end{array}$ & $\begin{array}{c}\text { Remesas/ } \\
\text { Importa } \\
\text { ciones }\end{array}$ & $\begin{array}{c}\text { Remesas/ } \\
\text { Balanza } \\
\text { Comercial }\end{array}$ & $\begin{array}{c}\text { Remesas/ } \\
\text { PIB }\end{array}$ \\
\hline $80-84$ & 67.40 & 8 & 7 & $(43)$ & 1.87 \\
$85-89$ & 160.38 & 24 & 15 & $(50)$ & 3.70 \\
$90-94$ & 655.92 & 72 & 34 & $(65)$ & 10.26 \\
$95-98$ & $1,157.93$ & 70 & 38 & $(74)$ & 10.60 \\
\hline
\end{tabular}

Fuente: revistas del Banco Central de Reserva de varios años. 
El ingreso masivo de recursos externos y su manejo macroeconómico han provocado el cambio de una economía típicamente agroexportadora a una nueva estructura productiva basada en actividades comerciales y de servicios ${ }^{3}$. A diferencia del modelo anterior donde el crecimiento de la economía salvadoreña se basaba en los flujos extemos provenientes de las exportaciones tradicionales, en los últimos años se han conformado dos nuevas situaciones que expresan la gran fragilidad del crecimiento actual. Por un lado, estos flujos se basan cada vez menos en las capacidades productivas internas. Por el otro, esos flujos se articulan y potencian más las actividades de servicios ${ }^{4}$.

\subsection{Una economía de servicios}

Los flujos de remesas familiares están favoreciendo un proceso de terciarización de la economía salvadoreña. Este proceso se caracteriza por el peso relativo que tiene el sector terciario en la economía. Durante la primera mitad de los años ochenta, el comercio y otros servicios representaban el 45.2 por ciento del producto interno bruto; sin embargo, dicha participación fue aumentando hasta alcanzar un 55.7 por ciento al final de los noventa. Por el contrario, el sector agropecuario y la minería redujeron su participación dentro del producto interno bruto, ya que pasaron de representar el 19.2 por ciento en la primera mitad de la década de los ochenta a menos del 14 por ciento en los años 1995-1998.

\section{Cuadro 2}

Estructura del PIB a precios constantes por tipo de actividades, período 1980-1998

( En porcentajes)

\begin{tabular}{l|r|r|r|r}
\hline & $80-84$ & $85-89$ & $90-94$ & $95-98$ \\
\hline Producto interno bruto & 100.0 & 100.0 & 100.0 & 100.0 \\
Agropecuario & 18.9 & 17.6 & 15.8 & 13.5 \\
Minería y canteras & 0.3 & 0.4 & 0.4 & 0.4 \\
Industria manufacturera & 21.8 & 21.1 & 21.6 & 21.3 \\
Construcción & 3.5 & 3.8 & 3.6 & 3.7 \\
Electricidad y agua & 1.0 & 1.2 & 0.7 & 0.5 \\
Comercio & 15.9 & 18.3 & 19.1 & 20.4 \\
Transporte, almacenaje y com. & 6.9 & 7.2 & 7.4 & 7.5 \\
Financiero y otros servicios & 2.3 & 2.4 & 2.3 & 3.3 \\
Otros servicios & 29.3 & 27.9 & 32.9 & 35.3 \\
\hline
\end{tabular}

Fuente: Revista del Banco Central de Reserva de varios años.

El proceso de terciarización implica un cambio fundamental ocurrido en el proceso de acumulación de capital del país, el cual se ha desplazado de las actividades agropecuarias a las actividades comerciales y de servicios. Lo preocu- 
pante del patrón de crecimiento de los noventa basado en las remesas familiares es que gira en torno a las actividades de importación y a los servicios. Mientras que antes de los años noventa, los flujos extemos surgían básicamente de unas actividades de producción que configuraban un eje de acumulación y de formación de capacidades internas, en la presente década lo hacen con unas actividades de servicios desvinculadas de procesos acumulativos internos ${ }^{5}$.

En cuanto al empleo, la agricultura absorbe más del 50 por ciento de la PEA ocupada rural, mientras que el 50 por ciento de la población económicamente activa urbana es absorbida por la industria y el comercio. A nivel nacional, la agricultura es el sector que más contribuye a la ocupación (27.7 por ciento) pero, al mismo tiempo, presenta los niveles de salarios promedios más bajos, lo que no permite superar la pobreza. Sin embargo, esta situación no afecta por igual tanto a la zona rural como a la zona urbana. En los últimos seis años, la agricultura ha contribuido a absorber alrededor de un 7 por ciento de la población económicamente activa urbana (Ver anexo 2). De allí, se puede establecer un nexo entre la permanencia de los niveles de pobreza rural y el estancamiento del agro.

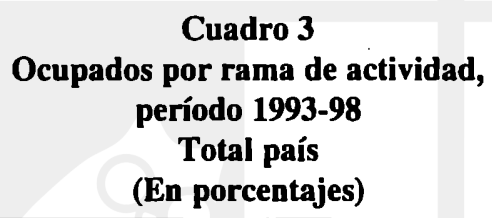

Cuadro 3

Ocupados por rama de actividad, periodo 1993-98

Total país

(En porcentajes)

\begin{tabular}{lrrrrrrr}
\hline & $92 / 93$ & 1994 & 1995 & 1996 & 1997 & 1998 & Promedio \\
\hline Ocupados & 100.0 & 100.0 & 100.0 & 100.0 & 100.0 & 100.0 & 100.0 \\
Agricultura & 32.9 & 28.0 & 27.0 & 28.1 & 26.3 & 24.0 & 27.7 \\
Minería & 0.1 & 0.1 & 0.1 & 0.1 & 0.1 & 0.1 & 0.1 \\
Industria & 18.4 & 19.6 & 19.3 & 18.0 & 16.1 & 19.5 & 18.5 \\
Electricidad y agua & 0.5 & 0.4 & 0.4 & 0.4 & 0.7 & 0.4 & 0.5 \\
Construcción & 5.0 & 5.8 & 6.6 & 6.4 & 6.7 & 5.9 & 6.1 \\
Comercio & 18.3 & 19.7 & 20.2 & 19.4 & 24.6 & 25.4 & 21.3 \\
Transp. y com. & 3.6 & 4.0 & 4.1 & 4.4 & 4.6 & 4.1 & 4.1 \\
Servicios financieros & 1.3 & 1.4 & 1.3 & 1.3 & 3.0 & 1.0 & 1.6 \\
Otros servicios & 19.9 & 21.2 & 21.0 & 21.8 & 17.8 & 19.6 & 20.2 \\
\hline
\end{tabular}

Fuente: Encuesta de Hogares de varios años.

\subsection{Una economía sesgada hacia lo urbano}

La década de los noventa se ha caracterizado por un incremento de la migración interna. Según la Dirección General de Estadísticas y Censos, aproximadamente 30 mil personas por año se trasladan desde el área rural hacia las ciuda- 
des $^{6}$. El flujo migratorio se explica por la búsqueda de mejores oportunidades de empleo e ingresos y de mejor acceso a educación y salud, debido a que las condiciones de vida en las zonas urbanas han presentado una mejora en términos generales por el hecho de que su población se ha visto favorecida por el patrón de crecimiento predominante, el cual se fundamenta en actividades terciarias e industriales ubicadas mayoritariamente en estas zonas.

Las encuestas de hogares y propósitos múltiples reflejan que el ingreso familiar promedio en las áreas rurales en 1998, sólo representó el 47.5 por ciento del ingreso urbano. Esta baja proporción se relaciona con el estancamiento de las actividades agropecuarias, las cuales son la principal fuente de ocupación rural; mientras que para el sector urbano es la actividad comercial. El salario promedio mensual para la agricultura sólo fue del 42.2 por ciento del sector comercial, en 1997. El costo de la canasta básica urbana para una familia de 4.3 personas representa el 70.5 por ciento del salario promedio mensual comercial, mientras que el costo de la canasta alimentaria rural para una familia de 5.3 personas representó el 126.1 por ciento del salario promedio mensual agrícola, en 1997.

La creciente urbanización, asociada en parte con el estilo de crecimiento, ha ejercido una presión a la concentración de las inversiones públicas en las áreas urbanas. Los insuficientes niveles de gasto público en infraestructura y servicios básicos en el área rural obstaculizan la reactivación agropecuaria, contribuyen al deterioro de la competitividad del sector y agudizan las condiciones de pobreza de la población rural?

Otro fenómeno relacionado con la urbanización y las características del proceso de terciarización es el auge del sector informal como generador de ocupación en las ciudades. En 1985, la participación del sector formal en la población económicamente activa urbana ocupada superaba en 15.8 puntos porcentuales la participación del sector informal, mientras que para 1998 esta diferencia era de 2.92. Los ingresos provenientes de esta actividad han contribuido a mejorar las condiciones de vida de la población urbana de menores recursos.

\section{La distribución del ingreso en El Salvador}

\subsection{Análisis de la evolución de la estructura distributiva}

El análisis de la distribución del ingreso en un país es importante para lograr un estudio más integral de la pobreza, ya que la concentración del ingreso es uno de los rasgos estructurales que evidencian la exclusión social de grandes segmentos de la población de los beneficios que puede traer el crecimiento económico.

Tradicionalmente, El Salvador ha estado caracterizado por una estructura distributiva muy concentrada, cuya evolución ha estado relacionada con la esta- 
Cuadro 4

Porcentaje de la PEA urbana ocupada, según condición de empleo

\begin{tabular}{lccc}
\hline Año & Sector formal & Sector informal & Total \\
\hline 1978 & 60.4 & 39.6 & 100 \\
1985 & 57.9 & 42.1 & 100 \\
1988 & 58.3 & 41.7 & 100 \\
$1992-93$ & 53.36 & 46.64 & 100 \\
1994 & 51.21 & 48.79 & 100 \\
1995 & 52.93 & 47.07 & 100 \\
1996 & 52.57 & 47.43 & 100 \\
1997 & 50.49 & 49.51 & 100 \\
1998 & 51.46 & 48.54 & 100 \\
\hline
\end{tabular}

Fuentes: Briones (1987), Hernández (1992)y y EHPM (varios años).

bilidad macroeconómica. Así, los peores niveles de concentración del ingreso se han presentado durante el período de tasas de crecimiento que históricamente han sido las más bajas y donde han existido las tasas más altas de inflación, es decir, durante la década de los ochenta.

La información más antigua disponible son cifras citadas por el Ministerio de Planificación en el Diagnóstico Económico Social de 1978-1983, las cuales indicaban que en 1950 el 31 por ciento de las familias salvadoreñas más pobres percibían el 7 por ciento del ingreso; en 1975 el 40 por ciento de las familias más pobres sólo recibían el 5 por ciento; siendo el 8 por ciento del total de familias del país las que acaparaban el mayor porcentaje de ingresos generado por todos los salvadoreños.

\section{Cuadro 5}

Estructura de distribución del ingreso en El Salvador ( En porcentajes) 1960-1990

\begin{tabular}{lrrrr}
\hline Población & 1960 & 1970 & $1980^{*}$ & 1990 \\
\hline 20\% más pobre & 5.5 & 3.7 & 2.0 & 4.48 \\
30\% más mediana & 10.5 & 14.9 & 10.0 & 15.75 \\
30\% sobre mediana & 22.6 & 30.6 & 22.0 & 28.57 \\
20\% más rico & 63.3 & 50.8 & 66.0 & 51.2 \\
\hline
\end{tabular}

* Principio del año.

Fuente: MIPLAN, CEPAL, EHPM (varios años). 
Recientemente, en el Informe del Estado de la Nación en Desarrollo Humano $1999^{11}$, se dedicó un apartado al análisis de la distribución del ingreso durante los años noventa. Se concluyó que la distribución del ingreso mejoró durante los noventa, aunque las diferencias tanto regionales como entre grupos son muy significativas. En este informe, se estudió la evolución de la estructura distributiva del ingreso para los años 1991/92, 1994 y 1997, a partir de la distribución del ingreso familiar mensual de los hogares por deciles con la información proporcionada por las encuestas de hogares y propósitos múltiples para dichos años.

Los resultados indicaban que el 10 por ciento más pobre de las familias recibían el 0.9 por ciento del ingreso en 1991/92 pasando a recibir el 1.9 por ciento en 1997; y el decil de más altos ingresos recibía, en 1991-1992, el 41.5 por ciento y en 1997, el 32.9 por ciento. A partir de la Encuesta de Hogares y Propósitos Múltiples de 1998, se puede establecer que el decil de menores ingresos pasó a recibir el 2.4 por ciento del ingreso total y el decil de mayores ingresos recibió el 32.5 por ciento, lo que refleja un aumento en la participación del primer decil de 0.5 por ciento y una disminución de la participación del último decil en 0.4 por ciento con respecto a 1997.

La mejora de la distribución del ingreso puede observarse a partir de la curva de Lorenz, la cual se encuentra cada vez más cerca de la línea de equidistribución. En el gráfico, se confunden la curva de Lorenz de 1997 con la de 1998, debido a que los cambios en la distribución del ingreso han sido mínimos, lo cual podría indicar que éstos no son estadísticamente significativos.

\section{Gráfico 2}

Curva de Lorenz

Evolución de la concentración del ingreso

1991/92-1998

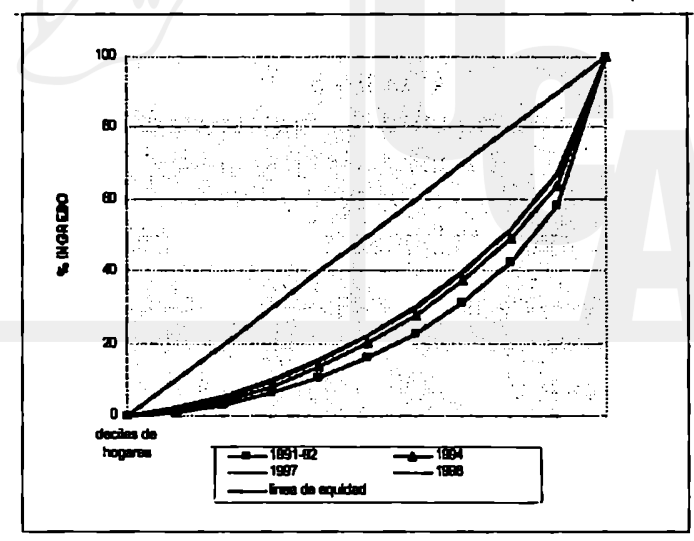

Fuente: Cálculos propios a partir de EHPM (varios años). 
Un indicador de la distribución del ingreso tradicionalmente utilizado es el coeficiente de Gini, el cual mide el grado en que la distribución del ingreso de las unidades familiares se desvía de una distribución perfectamente equitativa. Gráficamente, resulta de dividir el área entre la curva de Lorenz y la diagonal de igualdad perfecta entre el área total bajo la línea diagonal. El coeficiente de Gini se acerca a cero cuando existe una distribución del ingreso más equitativa y se acerca a uno cuando existe una estructura distributiva muy concentrada.

El coeficiente de Gini para 1995 presentaba un valor de 0.51, en 1997 de 0.49 y en base a cálculos propios en 1998 descendió levemente a $0.48^{\prime \prime}$. La mejora en la distribución del ingreso durante la década de los noventa ha estado relacionada con el flujo de remesas familiares y la creciente importancia del sector informal en la economía.

\section{Cuadro 6 \\ Indicadores de la concentración del ingreso (década de los noventa)}

\begin{tabular}{|c|c|c|c|c|c|c|}
\hline Años & GINI & $\begin{array}{c}\text { Decil } \\
\text { inferior }\end{array}$ & $\begin{array}{c}\text { Decil } \\
\text { superior }\end{array}$ & $\begin{array}{c}20 \% \text { más } \\
\text { pobre }\end{array}$ & $\begin{array}{l}20 \% \text { más } \\
\text { rico }\end{array}$ & $\begin{array}{c}60 \% \\
\text { medio }\end{array}$ \\
\hline $1991-92$ & - & $0.9 \%$ & 41.5 & $3 \%$ & 57.4 & 39.4 \\
\hline 1994 & - & 1.1 & 36 & 4 & 50.9 & 45.3 \\
\hline 1995 & 0.51 & - & - & - & - & - \\
\hline 1997 & 0.49 & 1.9 & 32.9 & 5.2 & 48.5 & 46.4 \\
\hline 1998 & 0.48 & 2.4 & 32.5 & 5.7 & 48 & 46.3 \\
\hline
\end{tabular}

Fuente: Banco Interamericano de Desarrollo, Informe Progreso Económico y Social 19981999; PNUD, Estado de la nación en Desarrollo, 1999, El Salvador; EHPM, Cálculos propios para 1998.

\subsection{Remesas familiares, distribución del ingreso e impacto en el consumo}

Uno de los factores que han incidido en la mejora de la estructura distributiva durante la década de los noventa son las remesas familiares, debido a que éstas contribuyen a incrementar el ingreso de los hogares de menores recursos. En tal sentido, las remesas tienen un impacto positivo en las condiciones de vida de la población y reducción de la pobreza, porque posibilitan un mayor acceso a bienes básicos de consumo, siendo éste el principal rubro al que se destinan las remesas familiares. 


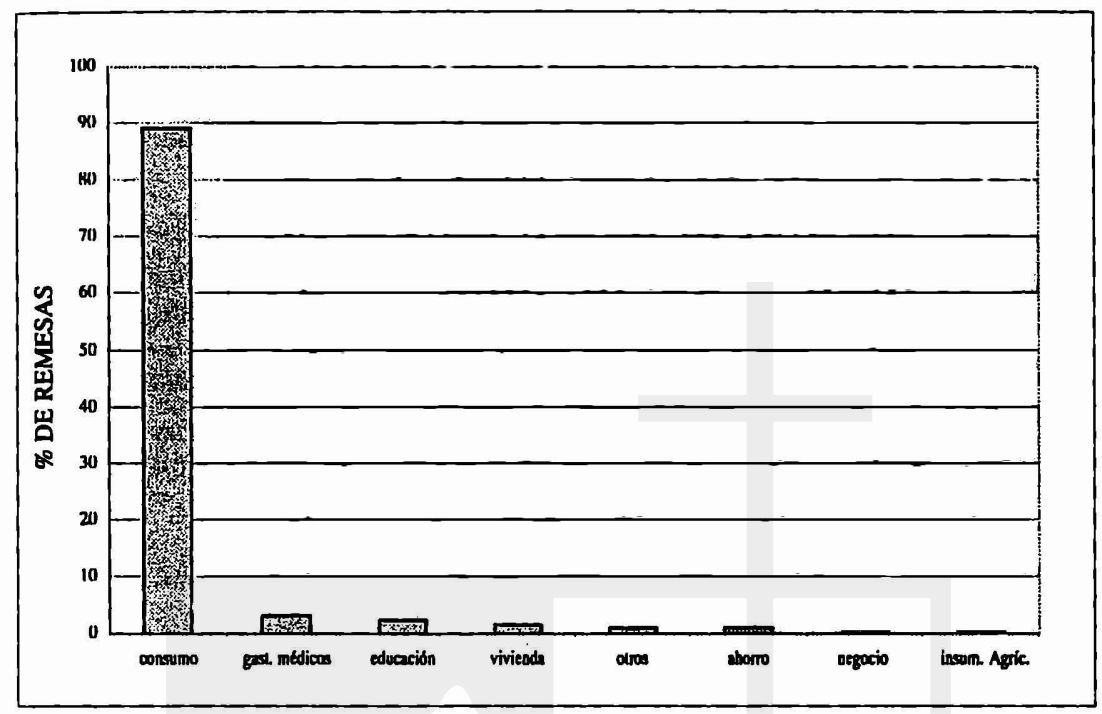

Fuente: EHPM 1998.

Un mecanismo para determinar el impacto de las remesas sobre la distribución del ingreso consiste en establecer su contribución al incremento de los ingresos totales de los estratos más bajos. El siguiente cuadro muestra que cuando se calcula la participación en el ingreso de cada decil, omitiéndose el valor de las remesas, la participación de los seis primeros deciles disminuye y la participación de los deciles con mayores ingresos se incrementa. Esto se explica debido a que son las familias de más escasos recursos las que reciben un porcentaje mayor del total de remesas recibidas anualmente, siendo el primer decil el que capta el 16.5 por ciento del total de remesas y el último decil sólo el 4.2 por ciento de las mismas. Es evidente que el flujo de remesas familiares tiene un impacto en la estructura distributiva del ingreso, ya que incrementa la participación de los primeros deciles en el ingreso total, debido a que son éstos los principales destinatarios de las remesas familiares. Por lo que se puede afirmar que la mejora en el coeficiente de Gini se debe principalmente a las remesas como factor exógeno y no al modelo del crecimiento vigente y a las bajas tasas de inflación. 


\section{Cuadro 7}

Remesas familiares, distribución del ingreso e impacto en el consumo 1998

\begin{tabular}{cccccc}
\hline Deciles & $\begin{array}{c}\text { \% Ingreso } \\
\text { total }\end{array}$ & \% Remesas & $\begin{array}{c}\text { \% Ingreso } \\
\text { sin remesas }\end{array}$ & $\begin{array}{c}\text { Déficit } \\
\text { consumo }\end{array}$ & $\begin{array}{c}\text { Déficit consumo } \\
\text { sin remesas }\end{array}$ \\
\hline 1 & 2.4 & 16.5 & 1.7 & -35.5 & -57.2 \\
2 & 3.3 & 12.8 & 2.8 & -38.7 & -50.3 \\
3 & 4.4 & 12.3 & 4.0 & -10.8 & -23.0 \\
4 & 5.7 & 11.5 & 5.4 & -17.2 & -25.4 \\
5 & 6.7 & 9.6 & 6.5 & 17.7 & 9.5 \\
6 & 8.2 & 10.3 & 8.0 & -8.0 & -13.7 \\
7 & 9.4 & 7.1 & 9.6 & 47.1 & 41.6 \\
8 & 11.9 & 8.7 & 12.0 & 29.5 & 24.9 \\
9 & 15.6 & 7.0 & 16.0 & 72.0 & 68.2 \\
10 & 32.5 & 4.2 & 33.9 & 136.2 & 134.8 \\
\hline Total & 100.0 & 100.0 & 100.0 & 44.5 & 38.6 \\
\hline
\end{tabular}

Fuente: EHPM 1998, cálculos propios.

Además, si se analiza la importancia de las remesas familiares en función de su contribución al consumo familiar, se obtiene que el déficit de consumo (definido como la parte del consumo no cubierta con los ingresos) de los primeros deciles se incrementa considerablemente cuando no se toman en cuenta las remesas familiares dentro del ingreso total. Para el primer decil, el déficit pasa de un $\mathbf{3 5 . 5}$ por ciento a un $\mathbf{5 7 . 2}$ por ciento, lo que muestra la relevancia de las remesas familiares para lograr mantener los niveles de pobreza actuales y no incrementar aún más las condiciones de miseria. A nivel general, si no se consideran las remesas dentro del ingreso total, el superávit en consumo disminuye pasando de un 44.5 a 38.6 por ciento, respectivamente. El superávit en consumo a nivel global de la economía se explica por los altos ingresos de los últimos deciles, ya que incluso son capaces de compensar el gran déficit que presentan los primeros.

El análisis anterior permite concluir que las remesas familiares han sido un factor determinante en la mejora de la distribución del ingreso. Lo que puede confirmarse aún más si se grafica la curva de Lorenz y se calcula el coeficiente de Gini con y sin remesas. En el Gráfico 4, la curva de Lorenz sin remesas se aleja de la línea de equidistribución y cuando se incluyen se acerca un poco más. El índice de Gini que se obtuvo para 1998 fue de 0.48 considerando el ingreso 
total y de 0.51 excluyendo las remesas. A pesar de la contribución de las remesas, los niveles de concentración siguen siendo altos, constituyéndose en un obstáculo para el desarrollo económico y social del país.

\section{Gráfico 4 \\ Curva de Lorenz \\ 1998}

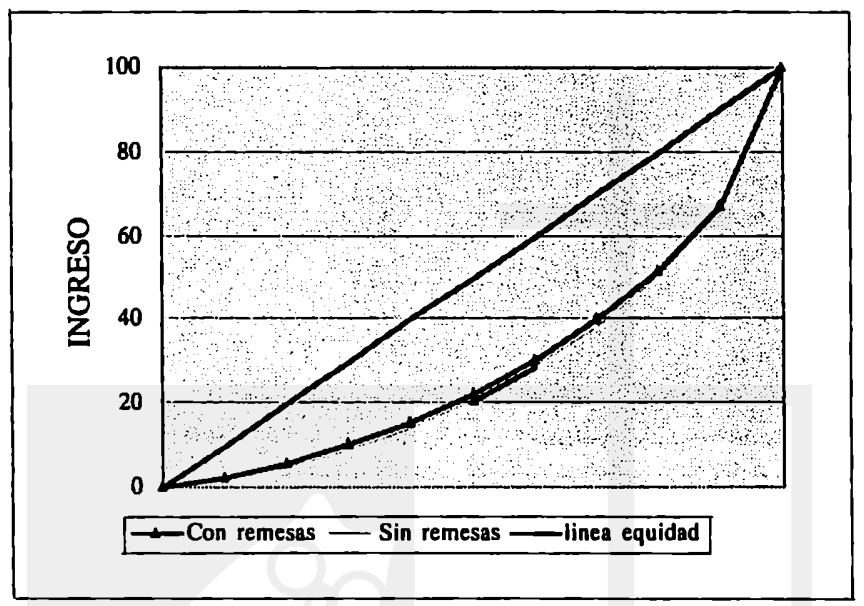

Fuente: Cálculos propios a partir de EHPM 1998.

\subsection{El sector informal y la distribución del ingreso}

Los ingresos que recibe la población ocupada en el sector informal urbano es otro de los elementos que tiene un efecto positivo sobre la estructura distributiva. $\mathrm{Al}$ igual que las remesas familiares, éstos contribuyen a incrementar la participación de los primeros deciles en el ingreso total, reduciendo así los niveles de pobreza urbana.

Al calcular el índice de Gini para 1998, excluyendo los ingresos del sector informal urbano del total de ingresos a nivel nacional, se obtuvo un índice de 0.52, lo que indica un incremento de 0.4 puntos en el índice de Gini para 1998. $\mathrm{El}$ incremento de desigualdad al excluir los ingresos del sector informal se ve reflejado en el siguiente gráfico. 


\section{Gráfico 5}

\section{Curva de Lorenz incluyendo y excluyendo sector informal 1998}

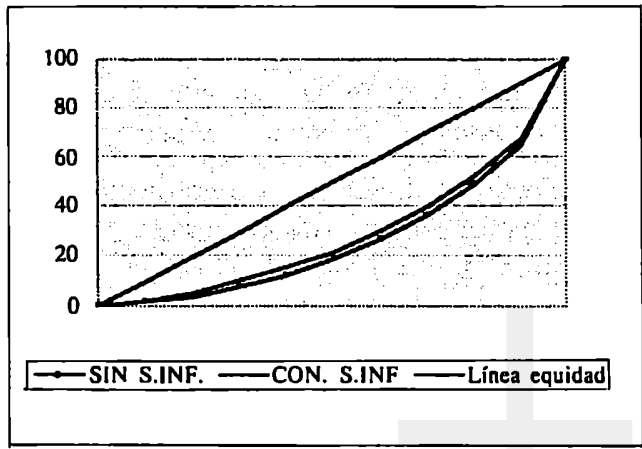

Fuente: Cálculos propios a partir de EHPM 1998.

\section{Análisis de la pobreza}

\subsection{Evolución de la pobreza en la década de los noventa}

En esta sección, se presenta una descripción de la evolución de la pobreza entre 1992 y 1998, en El Salvador. Se utiliza la información proporcionada por las Encuestas de Hogares y Propósitos Múltiples, donde la pobreza es calculada a partir de la línea de pobreza que se define por el costo de la canasta básica de consumo (2 CBA).

En general, se observa que el porcentaje de hogares en situación de pobreza bajó de 59.7 a 44.91 por ciento (Cuadro 8) lo que equivale a una reducción de 15.09 puntos. Sin embargo, existe una gran diferencia en la contribución de cada una de las áreas del país en dicha reducción. La pobreza bajó significativamente en las zonas urbanas (17.79 puntos) y levemente en las zonas rurales (4.86).

\section{Gráfico 6}

Evolución de la pobreza nacional (1992-98)

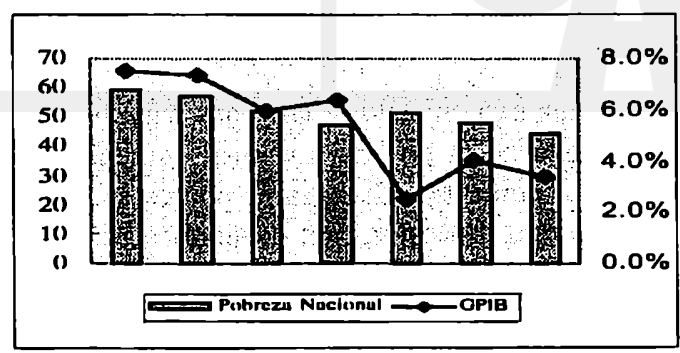


Esta disparidad entre la evolución de la pobreza rural y urbana está estrechamente relacionada con el patrón de crecimiento que ha estado fundamentado en el dinamismo de los sectores industriales y terciarios, los cuales están localizados mayoritariamente en las zonas urbanas. Los hogares pobres rurales no se han beneficiado del dinamismo global de la economía debido a que la mayoría de ellos, particularmente los hombres, trabajan en el sector agropecuario.

Para facilitar el análisis, se divide la serie de tiempo en dos subperíodos: el período de la recuperación económica (entre 1992 y 1995) y el de la desaceleración económica (entre 1996 y 1998). En el primer período, el porcentaje de hogares, cuyos ingresos per cápita no cubrían el costo de la canasta de consumo, se redujo en 12.36 puntos, consistente con el crecimiento del producto, En el cierre de este período (1995), la tasa de pobreza rural superaba en 18 puntos a la pobreza urbana -58.20 versus 40.02 - Sin embargo, pese a la mayor participación del sector urbano en la población total, la cantidad de hogares pobres era mayor en la zona rural que en la urbana.

\section{Gráfico 7}

Evolución de la pobreza rural y urbana (1992-98)

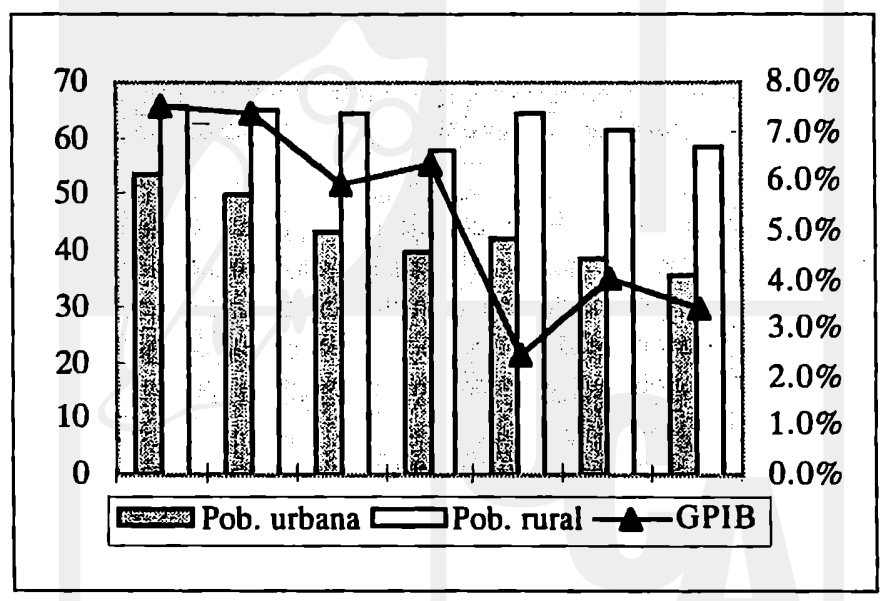

En 1.996, la economía experimentó la tasa más baja de crecimiento. En este mismo año, la incidencia de la pobreza nacional aumentó en 2.42 puntos. El mayor incremento en el porcentaje de hogares pobres se dio en el sector rural confirmando la tesis que la desaceleración económica no sólo afecta negativamente a la incidencia de la pobreza, sino que también castiga con mayor fuerza a los sectores donde la pobreza es más intensa. 
En los dos siguientes años, las cifras revelan una tendencia a la reducción de la pobreza, pero a una velocidad menor que la observada durante el período de la recuperación. Para 1998, 36 de cada 100 hogares urbanos eran pobres, pero esta proporción se elevó a 59 en la zona rural. Por otra parte, el incremento de la participación del sector urbano en el total de la población dio como resultado que tres de cada cinco hogares salvadoreños se encuentran en las zonas urbanas. Eso implica que, a nivel nacional, los hogares pobres estuvieran igualmente repartidos en ambos sectores. Sin embargo, el número de personas pobres en la zona rural es mayor que en la zona urbana (ver anexo 3). De los 3,052,977 de pobres, el 53.48 por ciento residen en la zona rural. El otro grupo de pobres, 1.42 millones de personas, habitan en la zona urbana. Ésta última alberga a 58 por ciento de la población total y a 46.52 por ciento de los pobres ${ }^{12}$.

\subsection{Evolución de la pobreza extrema}

La pobreza extrema se calcula a partir de una línea de indigencia que equivale al costo de la canasta básica de alimentos (1CBA). En general, durante el período de estudio, el porcentaje de hogares en situación de pobreza extrema se redujo en 10 puntos. Una vez más, las zonas urbanas tuvieron la mayor participación en la reducción; la pobreza en las zonas urbanas diminuyó en 10 puntos mientras que la pobreza rural sólo lo hizo en 5 puntos.

En el período de la recuperación económica, la proporción de los hogares pobres, cuyos ingresos per cápita no cubrian el costo de la canasta básica de alimentos, presentó una tendencia a la disminución pasando de 28.2 por ciento, en 1992, a un 18.23 por ciento, en 1995 . La situación era muy parecida en las zonas urbanas, donde la pobreza extrema se redujo en 11 puntos (de 23.3 a 12.44 por ciento).

Sin embargo, la pobreza extrema en la zona rural ha tenido un comportamiento diferente. En los tres primeros años que corresponden a los años de mayor crecimiento, hubo un leve aumento en la incidencia de la pobreza extrema y sólo en 1995 bajó significativamente (7.14 puntos). Este comportamiento de la pobreza extrema en el sector rural se explica porque los pobres extremos trabajan mayoritariamente (82.27 por ciento) en el sector agrícola, el cual no ha sido beneficiado del dinamismo de la economía.

La caída del producto, en 1996, ha afectado más a los pobres extremos rurales que a los urbanos. La pobreza extrema incrementó en 5.86 puntos en las zonas rurales, mientras que sólo aumentó en 1.8 puntos en las zonas urbanas. Tres de cinco de hogares pobres en situación de pobreza extrema estaban situados en el campo.

En 1997, se dio un descenso tanto en la pobreza extrema urbana como en lo rural. Sin embargo, los datos de la encuesta de hogares de 1998 indican un leve 


\section{Cuadro 8}

El Salvador: evolución de la pobreza, período 1991-1998

( porcentaje de hogares)

\begin{tabular}{|c|c|c|c|c|c|c|c|c|c|}
\hline \multirow[t]{2}{*}{ Años } & \multicolumn{3}{|c|}{ Total nacional } & \multicolumn{3}{|c|}{ Total urbana } & \multicolumn{3}{|c|}{ Total nural } \\
\hline & Extrema & Pobres & No pobre & Extrema & Pobres & No pobre & Extrema & Pobres & No pobre \\
\hline 91/92 & 28.2 & 59.7 & 40.3 & 23.3 & 53.8 & 46.2 & 33.6 & 66.1 & 33.9 \\
\hline $92 / 93$ & 27.00 & 57.51 & 42.49 & 20.83 & 50.46 & 49.54 & 33.78 & 65.25 & 34.75 \\
\hline 1994 & 23.94 & 52.42 & 47.58 & 16.33 & 43.84 & 56.16 & 34.78 & 64.62 & 35.38 \\
\hline 1995 & 18.23 & 47.53 & 52.47 & 12.44 & 40.02 & 59.98 & 26.46 & 58.20 & 41.80 \\
\hline 1996 & 21.89 & 51.69 & 48.31 & 14.54 & 42.44 & 57.56 & 32.24 & 64.84 & 35.16 \\
\hline 1997 & 18.50 & 48.05 & 51.95 & 12.01 & 38.68 & 61.32 & 27.91 & 61.61 & 38.39 \\
\hline 1998 & 18.94 & 44.61 & 55.39 & 12.94 & 36.01 & 63.99 & 28.74 & 58.66 & 41.34 \\
\hline
\end{tabular}

Fuente: EHPM de varios años.

aumento de 1 punto en los dos índices. En este último año, 29 de cada cien hogares rurales se encontraban en situación de pobreza extrema, mientras que la relación es de 13 por ciento en las zonas urbanas. A pesar de la mayor participación de la zona urbana en el total de la población, la pobreza extrema sigue siendo mayoritariamente una condición de los hogares rurales (ver anexo 4).

\subsection{Análisis de descomposición sectorial}

Utilizando la metodología propuesta por Ravallion y Datt ${ }^{13}$, se puede realizar una descomposición de los cambios en las tasas de pobreza total de los hogares en tres efectos: el efecto intrasectorial, que mide la contribución del sector rural o urbano en la reducción de la pobreza total; el efecto intersectorial, que puede ser interpretado como una medida de la correlación entre el cambio poblacional y la reducción de la pobreza, y el efecto interacción de las zonas, que es el residuo de los dos primeros efectos. La suma de los tres efectos debe de ser igual a 1 .

Entre 1992/93 y 1998, los resultados muestran que las ciudades dieron mayor aporte a la reducción tanto de la pobreza nacional como de la pobreza extrema. Esto es congruente con el patrón de crecimiento predominante que ha favorecido a los sectores urbanos. La disminución de la pobreza en la zona urbana contribuyó un 59 por ciento en la reducción de la pobreza total y un 51 por ciento en la disminución de la pobreza extrema; el aporte en la reducción de la pobreza del área rural fue de 24.3 y 29.8 por ciento, respectivamente. 


\section{Cuadro 9}

Descomposición sectorial de la pobreza 92/93-98

\begin{tabular}{lccccc}
\hline Tipo de pobreza & Variación & $\begin{array}{c}\text { Intra- } \\
\text { urbana }\end{array}$ & $\begin{array}{c}\text { Intra- } \\
\text { rural }\end{array}$ & $\begin{array}{c}\text { Inter- } \\
\text { sectorial }\end{array}$ & $\begin{array}{c}\text { Interacción } \\
\text { rural-urbana }\end{array}$ \\
\hline Pobreza & -12.9 & $58.6 \%$ & $24.3 \%$ & $11.1 \%$ & $6.00 \%$ \\
Pobreza extrema & -8.06 & $51.2 \%$ & $29.8 \%$ & $15.5 \%$ & $3.50 \%$
\end{tabular}

Fuente: Cálculos propios a partir de EHPM.

El cambio poblacional intersectorial, es decir, el cambio en la relación entre población urbana y población rural, contribuyó en un 11.1 por ciento en la disminución de la pobreza total y un 15.5 por ciento de la pobreza extrema. En efecto, hubo un incremento de 10 puntos en la participación de la población urbana en la población total. De ese modo, por cada 100 hogares en la zona rural existían 109 de la ciudad, en 1993, pero esta relación aumentó a 163 hogares urbanos, en 1998. Parte de este aumento es debido a la migración del campo a la ciudad que se explica por la búsqueda de mejores oportunidades de ingresos.

\subsection{Gasto social necesario para cerrar la brecha de pobreza e indigencia}

En el siguiente cuadro, se presenta el gasto social necesario para cerrar la brecha de la pobreza a partir de datos de la encuesta de hogares de 1998. Superar la pobreza cerrando la brecha implica invertir en promedio con perfecta focalización 354.63 colones al mes por persona, es decir, 12,992.275 millones de colones anuales para que esta población pobre pueda alcanzar el ingreso aceptable de la línea de pobreza. El gasto necesario estimado representa el 12.56 por ciento del producto interno bruto, un 76 por ciento del presupuesto de 1999 y un 71.30 por ciento del 2000 . Comparado con las cifras presentadas en la ley del presupuesto, el gasto social tendría que aumentar en un 92 por ciento.

Para erradicar la pobreza extrema, se hace necesario un gasto social mensual per cápita de 170.33 colones, es decir, un gasto social total de 2, 798.880 millones de colones al año, que representa un 2.70 por ciento del producto interno bruto y solamente un 16.40 y 15.40 por ciento del presupuesto de 1999 y del año 2000, respectivamente. Estos resultados permiten apreciar que erradicar la indigencia está al alcance del país, ya que sólo se necesita destinar el 41 por ciento de los fondos de desarrollo social del 2000 para cerrar la brecha de la extrema pobreza. 


\section{Cuadro 10}

Gasto social necesario (1998) ${ }^{14}$

\begin{tabular}{lcc}
\hline \multicolumn{1}{c}{ Criterios } & Pobreza & Indigencia \\
\hline Línea de pobreza por persona & 416.86 & 197.23 \\
Brecha de la pobreza & $85.07 \%$ & $86.32 \%$ \\
Déficit mensual per cápita & 354.63 & 170.33 \\
Déficit anual per cápita & 4255.56 & 2043.96 \\
Número de personas pobres & $3,052,977$ & $1,369,363$ \\
Déficit anual total' & $12,992.275$ & $2,798.880$ \\
Déficit anual total en dólares & $1,489.939$ & 320.972 \\
\% del presupuesto 1999 & $76 \%$ & $16.40 \%$ \\
\% del presupuesto 2000 & $71.30 \%$ & $15.40 \%$ \\
Proporción del gasto social 2000 & 1.92 veces & 0.41 veces \\
Proporción del PIB 1998 & $12.56 \%$ & $2.70 \%$ \\
\hline
\end{tabular}

1. Millones de colones.

2. Millones de dólares.

3. Presupuesto aprobado.

Fuente: Cálculos propios a partir de la EHPM 1998 y del Presupuesto general de la nación.

5. Lineamientos de política económica para el combate a la pobreza y la búsqueda de la equidad

\subsection{Aplicación de una política fiscal efectiva}

Uno de los objetivos de la política fiscal es impulsar el crecimiento sostenido para maximizar las posibilidades de desarrollo económico y social. Sin embargo, en el Salvador, la política fiscal enfrenta una fuerte contradicción: posee recursos limitados y demandas ilimitadas. Por lo que es urgente una reforma fiscal que conduzca a un incremento de los ingresos tributarios y que propicie las condiciones para incrementar el gasto público con el fin de contribuir a la erradicación de la pobreza.

\subsubsection{Necesidad de una reforma tributaria}

Es necesario realizar una reforma fiscal que contribuya al incremento de los recursos financieros del Estado y que asegure la asignación eficiente y la redistribución de los ingresos y activos, con el fin de reducir los niveles de pobreza actuales.

El Salvador se encuentra sistemáticamente clasificado entre los cinco países latinoamericanos con menores niveles de ingresos tributarios del gobierno central respecto al producto interno bruto ${ }^{15}$. La principal fuente de ingresos públicos 
es el impuesto al valor agregado (IVA), el cual ha experimentado un importante crecimiento en términos reales. En 1993 representaba el 4.8 por ciento del producto. interno bruto, tres años después alcanzó un 5.9 por ciento y en 1998 representó un 6.13 por ciento del producto. Si se analiza la eficiencia en la recaudación del IVA, lo cual está dado por un ratio que relaciona la recaudación efectiva en función de la recaudación potencial, se obtiene que éste se encuentra alrededor del 50 por ciento. Lo que implica que el complemento se pierde como resultado de la elusión, evasión y los incentivos fiscales ${ }^{16}$.

El único impuesto directo que ha sobrevivido a las reformas es el impuesto sobre la renta, el cual durante el período 1994-1997 ha presentado una mayor recaudación por concepto de sueldos y salarios que por las ganancias de las personas naturales, lo que confirma el incumplimiento del objetivo redistributivo de la política fiscal que se está aplicando en el país.

La situación de las finanzas públicas en El Salvador dificulta una verdadera estrategia de distribución del ingreso y de reducción de la pobreza, debido al carácter regresivo de la estructura tributaria y por la insuficiencia de los ingresos públicos para financiar el gasto, teniéndose que recurrir a financiamiento vía deuda.

En tal sentido, una reforma fiscal que tenga como objetivo el fomento del crecimiento económico, que se traduzca en mejoras en la distribución del ingreso y la reducción de la pobreza, debe llevar consigo los siguientes puntos: (a) La estructura tributaria debe poseer un carácter progresivo, lo que implica incrementar sustancialmente la participación del impuesto a la renta e introducir el impuesto predial, con el fin de garantizar que las personas y empresas de mayores recursos paguen efectivamente más impuestos que las de menores ingresos. (b) Se debe combatir la evasión y elusión fiscal para lograr una mejor recaudación tributaria.

\subsubsection{El gasto público}

Los esfuerzos que se realizan para la obtención de mayores niveles de recaudación deben acompañarse de una mayor efectividad, eficiencia y equidad del gasto público.

Uno de los primeros pasos debe ser incrementar la productividad del gasto público, ya que pese a las políticas de reducción del Estado, el gasto corriente posee una mayor participación en el presupuesto público ( 77 por ciento en el 2000) con relación a las erogaciones destinadas a la inversión en capital (15 por ciento) ${ }^{17}$. Lo que. genera preocupación debido a que éste último es un factor clave para el crecimiento de la economía, ya que sólo a través de inversiones en capital humano y en infraestructura se podrá lograr un crecimiento sostenido a largo plazo. 


\subsubsection{Gasto social}

Una estrategia de combate a la pobreza debe ir acompañada de una política de gasto social efectiva. En apartados anteriores, se mostró la importancia y la necesidad de incrementar el gasto social para cerrar la brecha de la pobreza. En éste, se estudian el mecanismo y las áreas prioritarias de inversión del gasto social.

Pueden distinguirse tres tipos de políticas sociales que contribuyen al combate de la pobreza ${ }^{18}$ : (a) Las políticas de compensación social, que se orientan hacia los grupos afectados por las transformaciones económicas (corto plazo) y no garantizan por sí mismas la erradicación de la pobreza. (b) Las políticas de integración social, que están orientadas a superar la marginalidad en la que se encuentran diferentes grupos sociales, afectados por distintas formas de exclusión. (c) Políticas de inversión en capital humano, que buscan dotar a la población de las calificaciones necesarias para un mejor desempeño laboral; éstas son políticas de largo plazo que buscan eliminar la pobreza.

Todos los tipos de política social son importantes en una estrategia de combate a la pobreza. Las dos primeras políticas deben orientarse a aliviar la situación de pobreza y a evitar que ésta se reproduzca a escala ampliada. Sin embargo, se debe privilegiar la inversión en capital humano, si realmente se quiere erradicar la pobreza y no solamente reducirla, ya que a través de mayor educación y salud se logrará el desarrollo de las capacidades humanas y la estabilidad de los ingresos a largo plazo.

Si bien la inversión en capital humano es una condición necesaria para la erradicación de la pobreza, ésta no es suficiente. Uno de los requisitos fundamentales que debe cumplir para contribuir a la equidad y al combate de la pobreza es su focalización.

Focalizar es reconocer a los pobres como población objetivo y orientar la política social a mejorar el acceso de éstos a los bienes y servicios básicos y a fomentar su integración en la sociedad. La focalización no es una política social, es un instrumento a su servicio. Sin embargo, se reconoce que la aplicación de este mecanismo hace más eficaz y eficiente a la política social, en la mejora de la distribución del ingreso y en la erradicación de la exclusión social.

Estudios de la CEPAL ${ }^{19}$ indican que El Salvador se encuentra catalogado como uno de los pocos países que, en el período 1996-1997, no habían presentado mejoras a nivel del gasto per cápita respecto a los inicios de la década de los ochenta, presentando niveles de gasto social inferiores a los del comienzo de éste período. En tal sentido, El Salvador se encuentra clasificado en condición de gasto social bajo, en relación con otros países latinoamericanos.

Como consecuencia del bajo gasto social, El Salvador presenta una amplia brecha en los niveles de gasto en relación con el promedio regional, pero ésta se ha 
venido ampliando principalmente en el gasto destinado a educación y seguridad social.

\section{Cuadro 11 \\ Tendencias del gasto social por sectores, gasto social real per cápita, 1997}

(En dólares)

\begin{tabular}{lcccrrrrrr}
\hline & \multicolumn{2}{l}{ Educación } & \multicolumn{2}{c}{$\begin{array}{c}\text { Salud } \\
\text { y nutrición }\end{array}$} & $\begin{array}{c}\text { Seguridad } \\
\text { social }\end{array}$ & \multicolumn{2}{c}{$\begin{array}{c}\text { Vivienda, agua y } \\
\text { saneamiento }\end{array}$} \\
\hline Período & $90-91$ & $96-97$ & $90-91$ & $96-97$ & $90-91$ & $96-97$ & $90-91$ & $96-97$ \\
\hline La región & 87 & 122 & 84 & 110 & 162 & 229 & 37 & 44 \\
El Salvador & 33 & 50 & 28 & 54 & 22 & 39 & 3 & 5 \\
Diferencia & 54 & 72 & 56 & 56 & 140 & 190 & 34 & 39 \\
\hline
\end{tabular}

Fuente: CEPAL, Panorama social de América Latina 1998.

Ante tal situación, se deben incrementar y utilizar eficientemente los recursos destinados al gasto social, pero principalmente aquellos que contribuyan a mejorar las capacidades y habilidades de las personas. Entre las principales áreas de inversión se encuentran la educación y la salud.

La inversión en educación es fundamental porque ayuda a reducir la pobreza por lo menos de tres maneras. Primero, brinda a los trabajadores del mañana las habilidades que necesitan para escapar de la trampa de la mano de obra no calificada y con baja remuneración. De esta manera, se reduce la oferta abundante de mano de obra no calificada y se aumentan los salarios medios. Segundo, una fuerza de trabajo mejor preparada aumenta la competitividad y las perspectivas de exportaciones y de mayores tasas de crecimiento. Finalmente, el mejoramiento del nivel de educación elemental de la fuerza de trabajo mejorará la distribución del ingreso, porque reducirá las grandes diferencias por especialización que reciben los más educados ${ }^{211}$.

La buena salud constituye un componente clave del bienestar y, por consiguiente, la prestación de servicios de salud a los pobres es un medio que el gobierno tiene a su disposición para mejorar la situación de éstos. Aunque ésta no contribuya a crear oportunidades para mejorar los ingresos, mejora la productividad y capacidad de aprendizaje de las personas. Por consiguiente, los gastos en salud pueden justificarse porque mejoran la situación de los pobres y porque realizan su potencial de ingresos ${ }^{21}$. 


\subsection{Fomentar el desarrollo agropecuario}

Una de las razones para considerar al agro como un sector fundamental en la economía es su importancia en la generación de ingresos y empleo para las zonas rurales. En este sentido, toda estrategia que busque reducir la brecha entre la pobreza rural y urbana debe incorporar dentro de la agenda el fomento del desarrollo agropecuario.

En las zonas rurales, se encuentra alrededor del 42 por ciento de la población del país, quienes han vivido marginados de los frutos del crecimiento económico y presentan niveles de pobreza mayores a los de la zona urbana. Esto se explica, en gran medida, por el desempeño mediocre del sector agropecuario durante los noventa debido a la reducción en los márgenes de utilidad de las actividades transables, causada parcialmente por la persistente apreciación de la moneda, un pobre comportamiento de los productos tradicionales, el atraso tecnológico generado por falta de innovación durante los largos años de conflicto y el bajo desarrollo del capital humano entre productores, el pobre estado de la red de carreteras, los pobres resultados del proceso de reforma agraria y por la situación de mayor violencia e inseguridad ${ }^{22}$.

Se debe reconocer que el deterioro del agro salvadoreño está asociado, en gran parte, a los efectos de la política económica implementada y no es el resultado natural de la poca rentabilidad y competitividad de estas actividades. Por lo tanto, es necesario adoptar medidas de política económica que no excluya de los beneficios del crecimiento económico a la población rural, ya que, como se mencionó anteriormente, una estrategia de combate a la pobreza debe estar basada en el crecimiento económico de las actividades donde se encuentran laborando los pobres.

Lo anterior no implica que se considere que el sector agropecuario debe ser el principal eje de acumulación del país, pero sí que debe fomentar su reactivación de cara al combate de la pobreza estructural que presentan las zonas rurales y como parte de la noción de desarrollo económico basado en la sostenibilidad ecológica.

Una estrategia de desarrollo agropecuario debe incluir, por lo menos, los siguientes elementos: asistencia técnica para mejorar la productividad de las cosechas; acceso a servicios financieros para los pequeños agricultores; inversión en infraestructura que facilite la comercialización agrícola, y evitar la sobrevaluación de la moneda

\subsection{Apoyo a la microempresa}

Las actividades microempresariales han cobrado auge durante la década de los noventa, como consecuencia del patrón de crecimiento durante estos años. Aunque El Salvador ha tenido tasas de crecimiento económico positivas, los 
índices de desempleo abierto y subempleo afectan a cerca del 50 por ciento de la población económicamente activa. En tal sentido, la microempresa se ha convertido en un medio que ha contribuido significativamente a generar ocupación y a reducir los niveles de pobreza principalmente urbano ${ }^{23}$.

A partir de la encuesta de la dinámica microempresarial de 1998, se puede constatar la importancia de la microempresa en la generación de ingresos de subsistencia y ocupación a la población más pobre. Se establece que del total de microempresarios, el 76.9 por ciento se encontraba ubicado en la zona urbana. La inmensa mayoría son microempresas de subsistencia $\left(88.4\right.$ por ciento) ${ }^{24}$ y acumulación simple (7.1 por ciento) ${ }^{25}$. Para este año, el 33.9 por ciento de la PEA total se encontraba empleada en actividades microempresariales, y el 72 por ciento de los microempresarios declararon que su única fuente de ingresos proviene del desarrollo de la actividad microempresarial.

Además de la contribución de la microempresa a la reducción de la pobreza, este sector es importante por su interrelación con el resto de sectores de la economía (con los llamados sectores modernos), y por su contribución en el producto interno bruto, se estima que su aporte se situó alrededor del 24 y 36 por ciento del PIB, entre 1992 y 1995, ubicando a El Salvador como uno de los países de la región en donde su contribución es más determinante ${ }^{26}$.

Dos de las principales áreas que deben de ser potenciadas para mejorar la productividad y los ingresos de las microempresas son:

- Mejorar la capacidad productiva y organizacional de la microempresa a través de la inversión en capital humano, ya que el nivel educativo de los propietarios y de la mano de obra que laboran en la microempresa es bastante bajo, tal como se confirma con los resultados de la encuesta microempresarial de 1998, en donde el 18.8 por ciento de los microempresarios no poseían ningún nivel educativo, el 21.5 por ciento poseía. educación básica, sólo un 3.9 tenía un nivel educativo superior y el 90 por ciento de ellos no habían recibido ninguna capacitación para desempeñar su trabajo.

- Promover el acceso a servicios financieros, con el fin de fomentar la inversión en rubros que incrementan la capacidad productiva y que mejoran la calidad de los servicios prestados. En 1998, la demanda potencial de crédito ascendía a 6,573 millones de colones, lo cual representaba los requerimientos del 62 por ciento del total de microempresarios. Sin embargo, existe una gran dificultad para satisfacer esta demanda por parte de las instituciones financieras tradicionales, por lo que es importante que el Estado fomente el desarrollo de identidades financieras encargadas de atender a este sector de la economía. 


\subsection{Inversión productiva de las remesas familiares}

El uso productivo de las remesas está relacionado con el ahorro y la inversión (tanto física como humana). En tal sentido, el fomento de la productividad de las remesas es necesario para lograr un crecimiento económico estable y sostenido en el largo plazo, que propicie un ambiente favorable para la erradicación de la pobreza.

Se pueden distinguir tres tipos de medidas que han sido fomentadas por los gobiernos con el fin de utilizar de manera productiva las remesas ${ }^{27}$ : (a) las orientadas a aumentar el flujo de remesas y facilitar el ahorro del emigrante en los bancos del país de origen; $(b)$ las dirigidas a fomentar el ahorro y la inversión entre los receptores; y $(c)$ las que tienen como fin promover directamente proyectos de desarrollo comunitario o de tipo productivo, financiados total o parcialmente con remesas colectivas.

La debilidad de la primera medida es que no contribuye necesariamente a la inversión ni a proyectos con impacto directo en la producción y empleo. Muchas veces, la segunda crea una dependencia negativa entre los receptores. En cuanto a la tercera medida, estudios realizados encontraron que este tipo de proyectos son, en su mayoría, sobre desarrollo comunitario y que los de tipo productivo son aún muy escasos. Sin embargo, se considera a las remesas colectivas como un mecanismo que podría contribuir al uso productivo de las mismas, aunque no han mostrado la efectividad necesaria.

Una mejor forma de promover la maximización de los efectos positivos de las remesas debe consistir en financiar con estos recursos externos a los inversionistas, con la condición de que destinen estos fondos a la adquisición de capital, privilegiándose las importaciones productivas y no las de consumo. Esto implica la creación de líneas de crédito especiales en condiciones favorables. Por eso, es necesario minimizar el efecto negativo que produce el manejo macroeconómico de las remesas sobre las tasas de interés activas, como una de las condiciones para fomentar su uso productivo. De este modo, se podrá lograr un mayor impacto sobre la inversión nacional.

El papel del Estado debe consistir en crear el ambiente adecuado y las condiciones necesarias para la utilización productiva de las remesas familiares, por lo que se debe revisar la política monetaria y fiscal con el fin de garantizar un escenario macroeconómico que fomente la inversión.

\section{Conclusiones}

1. El Salvador ha experimentado una recuperación en la tasa de crecimiento durante la década de los noventa. Sin embargo, dicho crecimiento ha sido frágil, dado que ha estado sustentada en las remesas familiares que, por su manejo macroeconómico, ha potenciado el desarrollo de actividades relacio- 
nadas con el ámbito de la circulación; además, ha sido dual en el sentido que ha favorecido más a la población urbana. Por lo que se hace necesario una revisión de la estrategia económica vigente, con el fin de garantizar un crecimiento estable y sostenido que se fundamente en el dinamismo de los sectores donde trabajan los pobres.

2. La década de los noventa se ha caracterizado por una mejora en la distribución del ingreso, aunque los niveles de concentración todavía son altos. Dicha mejora se debe principalmente a factores externos (remesas familiares) y a las actividades de subsistencia (sector informal). Ambos elementos son los principales determinantes del incremento de los ingresos de los estratos más bajos de la población, remplazando así los efectos no generados por la política económica implementada, la cual ha dado lugar a una estructura tributaria y una estructura de gastos regresivas.

3. También en la década se ha dado una reducción en los niveles de pobreza presentados por los hogares, tanto urbanos como rurales. Sin embargo, los niveles de pobreza no han tenido un comportamiento estable, guardando una relación inversa con las fluctuaciones de la tasa de crecimiento del producto.

Por medio del análisis de la descomposición sectorial de la pobreza, se evidencia que la zona urbana ha contribuido más a la reducción de la pobreza y pobreza extrema. La menor participación de la zona rural en la disminución de la pobreza se explica por el hecho de que no se ha visto favorecida por el patrón de crecimiento vigente. De ahí surge la necesidad de fomentar el desarrollo rural y del sector agropecuario, como mecanismos para avanzar en la reducción de la pobreza y para lograr un crecimiento sostenido.

4. Los ingresos adicionales que necesitan los pobres para alcanzar la línea de pobreza son bastante altos. La brecha de ingresos de los pobres equivale aproximadamente al 85 por ciento, lo que implica que su ingreso promedio cubre solamente el 15 por ciento de la línea de pobreza. Para cerrar la brecha de la pobreza y pobreza extrema se hace necesario un gasto social que represente el 192 y 41 por ciento, respectivamente, de los fondos de desarrollo social; lo cual indica que con el uso eficiente de los recursos a partir de su perfecta focalización, es posible erradicar la indigencia en un plazo reducido y sólo se requiere voluntad política.

5. El combate a la pobreza y la búsqueda de la equidad implica privilegiar a la inversión en capital humano y fomentar el desarrollo de las actividades donde laboran los pobres. Teniendo en cuenta lo anterior, se debe priorizar al desarrollo agropecuario y al fomento de las actividades microempresariales en una estrategia eficaz de combate a la pobreza. Además, la política fiscal debe cumplir con su objetivo redistributivo. 


\section{Referencias bibliográficas}

Altimir, Oscar. "Changes in Inequality and Poverty in Latin America". Santiago, Chile, 1995.

Banco Interamericano de Desarrollo. "América Latina frente a las desigualdades, Informe Progreso económico social 1998-1999".

Banco Interamericano de Desarrollo. "Estrategia para reducir la pobreza", marzo, 1997.

Beccaria, Luis; Boltvinik, Julio; Feres, Juan Carlos; Fresneda, Oscar; Leon, Arturo y Sen,

Amartya. America Latina: El reto de la pobreza, características, evolución y perspectivas. Bogota: UNDP, 1992.

Briones, Carlos. Microempresa y transformación productiva, FLACSO, 1998.

CEPAL. La brecha de la equidad, 1997.

CEPAL. Panorama social de América Latina 1998.

CEPAL. "Uso productivo de las remesas en El Salvador, Guatemala y Nicaragua", LC/ MEX. 622, septiembre, 1998.

CND. Temas claves para el plan de nación: consulta especializada, 1999.

Cox Edwards, Alejandra. Alternativas de politica económica frente al problema de la pobreza en El Salvador, abril, 1999.

Datt y Ravallion. "Growth and Redistribution Components of Changes in Poverty Measure: Descomposition with Application to Brazil and India in the 1980", Living standards measurement study, working paper, 83, World Bank, 1991.

Departamento de Economía. "Análisis de coyuntura económica", ECA, septiembre, 1999, UCA.

FOMMI. Libro Blanco de la microempresa, El Salvador, 1997.

FUNDE. Crecimiento estéril o desarrollo, 1996.

FUSADES. Crecimiento con participación: una estrategia de desarrollo para el siglo XXI, abril, 1999.

Larrain y Vergara. Income Distribution, Investment and Growth, Development Discussion papers, 596, agosto, Harvard college, 1997.

Lazo, Francisco. Pobreza, distribución del ingreso y necesidades de crecimiento real en El Salvador, Cinas, julio, 1994.

Lustig, Nora. "Introduction" in Coping with Austerity: Poverty and Inequality in Latin America, Washington DC: The Brookings Institution, 1995.

Morales, Armando. "Sources of growth", 1998, MF papers.

Moreno, Raúl. "La reforma fiscal en El Salvador: Una exigencia impostergable", Scric de Alternativas para el Desarrollo, 58, FUNDE, 1999.

Morley, Samuel. Poverty and Inequality in Latin America: The Impact of Adjustment and Recovery in the 1980s. Baltimore: The Johns Hopkins University Press, 1995.

Nina Esteban y Aguilar Ana. "Amartya Sen y el estudio de la desigualdad cconómica y la pobreza monetaria", Cuaderno de Economía, 29, Universidad Nacional de Colombia, 1998.

PNUD, Estado de la Nación en Desarrollo 1999, El Salvador.

Psacharopoulos, George; Morley, Samuel; Fiszbein, Aricl; Lee, Haeduck y Wood, William. "Poverty and Income Inequality in Latin Amcrica During the 1980s". Review of Income and Wealth, Scries 41, 3, 1995, pp. 245-264.

Ravallion, Mạrtin y Shaohua Chen. "What Can New Survey Data Tell Us about Recent Changes in Distribution and Poverty?", The World, 1997. 
Segovia, Alexander. Cambio estructural, políticas macroeconómicas y pobreza en El Salvador, diciembre, 1997.

\section{Anexo metodológico}

\section{Descomposición de la pobreza (Datt y Ravallion 1991)}

La descomposición mide los cambios en la pobreza de los hogares entre sectores (por ejemplo, entre la población urbana y la rural o por nivel de educación del jefe del hogar) y su relación con el cambio de pobreza dentro del mismo sector.

P98 - P92/93 = (Pr98 - Pr92/93)nr92/93 + (Pu98 - Pu92/93)nu92/93 + ¿(ni98 - ni92/ 93)Pi92/93 + $($ (Pi98 - Pi92/93)(ni98 - ni92/93)

Los efectos sectoriales son:

$\sum(\mathrm{Pi} 98$ - Pi92/93)ni92/93 es el cambio intrasectorial en la pobreza del sector $\mathrm{i}$

$\sum($ ni98 - ni92/93)Pi92/93 es el cambio intersectorial en la pobreza debido a los cambios poblacionales

$\sum(\mathrm{Pi} 98$ - Pi92/93)(ni98 - ni92/93) es la interacción entre los cambios sectoriales y los cambios poblacionales.

Donde

P98 : Porcentaje de hogares pobres en 1998.

P92/93 : Porcentaje de hogares pobres en 1992/93.

Pit : Porcentaje de hogares pobres en el sector $i$ en el año $t$.

Nit : Proporción de la población total en el sector i en el año t.

Anexos estadísticos

\section{Anexo 1}

Hogares que reciben remesas

por área geográfica

1992/93-1998

(En porcentajes)

\begin{tabular}{lcccccc}
\hline & $92 / 93$ & 94 & 95 & 96 & 97 & 98 \\
\hline Total pais & 14.37 & 15.56 & 15.34 & 15.05 & 14.64 & 18.82 \\
Rural & 13.15 & 15.10 & 14.15 & 14.40 & 14.00 & 18.70 \\
Urbana & 15.49 & 15.88 & 16.20 & 15.51 & 15.08 & 18.88 \\
\hline
\end{tabular}

Fuente: cálculos propios a partir de EHPM (varios años). 
Anexo 2

Ocupados por rama de actividad

período 1992-1998

(En porcentajes)

\begin{tabular}{|c|c|c|c|c|c|c|}
\hline Rural & $92 / 93$ & 94 & 95 & 96 & 97 & 98 \\
\hline Agricultura & 61.16 & 59.47 & 56.35 & 58.65 & 55.65 & 51.73 \\
\hline Minería & 0.14 & 0.12 & 0.04 & 0.12 & 0.04 & 0.11 \\
\hline Industria & 12.15 & 12.72 & 12.47 & 11.65 & 10.93 & 13.61 \\
\hline Electricidad y agua & 0.14 & 0.20 & 0.27 & 0.20 & 0.31 & 0.24 \\
\hline Construcción & 4.28 & 5.11 & 6.28 & 5.86 & 6.22 & 5.68 \\
\hline Comercio & 11.14 & 10.90 & 11.77 & 10.14 & 13.77 & 14.84 \\
\hline Transp. y com. & 2.06 & 1.96 & 2.05 & 1.88 & 2.34 & 1.91 \\
\hline Servicios financieros & 0.22 & 0.26 & 0.18 & 0.23 & 0.82 & 0.23 \\
\hline Servicios & 8.71 & 9.24 & 10.60 & 11.28 & 9.91 & 11.66 \\
\hline Total & 100.0 & 100.0 & 100.0 & 100.0 & 100.0 & 100.0 \\
\hline \multicolumn{7}{|l|}{ Urbano } \\
\hline Agricultura & 8.5 & 7.0 & 7.0 & 7.0 & 6.6 & 6.7 \\
\hline Minería & 0.1 & 0.1 & 0.1 & 0.1 & 0.1 & 0.1 \\
\hline Industria & 23.8 & 24.2 & 24.0 & 22.4 & 19.6 & 23.1 \\
\hline Electricidad y agua & 0.9 & 0.5 & 0.5 & 0.5 & 1.0 & 0.6 \\
\hline Construcción & 5.7 & 6.2 & 6.8 & 6.8 & 6.9 & 6.1 \\
\hline Comercio & 24.5 & 25.5 & 26.0 & 25.8 & 31.9 & 31.9 \\
\hline Transp. y com. & 5.0 & 5.3 & 5.6 & 6.2 & 6.2 & 5.4 \\
\hline Servicios financieros & 2.2 & 2.1 & 2.1 & 2.1 & 4.5 & 1.6 \\
\hline Servicios & 29.5 & 29.1 & 28.1 & 29.1 & 23.2 & 24.6 \\
\hline Total & 100.0 & 100.0 & 100.0 & 100.0 & 100.0 & 100.0 \\
\hline
\end{tabular}

Fuente: EHPM (varios años). 
Anexo 3

Distribución geográfica de los hogares pobres Período 92/92-98

\begin{tabular}{lccc}
\hline Año & Zona & Porcentajes de la población & Incidencia \\
\hline $92 / 93$ & Urbano & 52.34 & 45.92 \\
94 & Rural & 47.66 & 54.07 \\
& Urbano & 58.72 & 49.11 \\
95 & Rural & 41.28 & 50.88 \\
& Urbano & 58.70 & 49.43 \\
96 & Rural & 41.23 & 50.49 \\
& Urbano & 58.70 & 48.20 \\
97 & Rural & 41.30 & 51.80 \\
& Urbano & 59.14 & 47.61 \\
98 & Rural & 40.86 & 52.39 \\
& Urbano & 62.01 & 50.06 \\
& Rural & 37.99 & 49.95 \\
\hline
\end{tabular}

Fuente: Cálculos propios a partir de EHPM de varios años.

Anexo 4

Distribución de los hogares en extrema pobreza período 92/93-98

\begin{tabular}{l|ccc}
\hline Año & Zona & Porcentajes de la población & Incidencia \\
\hline $92 / 93$ & Urbano & 52.34 & 40.38 \\
& Rural & 47.66 & 59.63 \\
94 & Urbano & 58.72 & 40.06 \\
& Rural & 41.28 & 59.97 \\
95 & Urbano & 58.70 & 40.06 \\
& Rural & 41.23 & 59.85 \\
96 & Urbano & 58.70 & 38.99 \\
& Rural & 41.30 & 60.82 \\
97 & Urbano & 59.14 & 38.39 \\
& Rural & 40.86 & 61.64 \\
98 & Urbano & 62.01 & 42.37 \\
& Rural & 37.99 & 57.64 \\
\hline
\end{tabular}

Fuente: Cálculos propios a partir de EHPM de varios años. 
* Los autores hacen expreso su agradecimiento al Prof. Francisco Lazo por sus comentarios y al Prof. Alvaro Trigueros por su valiosa colaboración para que este trabajo pudiera realizarse.

1. Banco Interamericano de Desarrollo, Estrategia para reducir la pobreza, marzo, 1997 , p. 4.

2. Cox Edwards, Alejandra, Alternativas de política económica frente al problema de la pobreza en El Salvador, abril, 1999, p. 2.

3. Segovia, Alexander, Cambio estructural, políticas macroeconómicas y pobreza en El Salvador, diciembre, 1997, p. 4.

4. FUNDE, Crecimiento estéril o desarrollo, 1996, p. 69.

5. Idem, p. 70.

6. CND, Temas claves para el plan de nación: consulta especializada, 1999, p. 107.

7. Idem, p. 44.

8. Briones, Carlos, "Un ensayo de descripción de las características del Sector Informal urbano salvadoreño", Boletín de ciencias económicas UCA, julio-agosto, 1987.

9. Hernández, Vilma, Estimación de la magnitud y características del sector informal en El Salvador. INCAE, San José, Costa Rica, 1992.

10. PNUD, Estado de la Nación en Desarrollo 1999, El Salvador, pp. 19 y 20.

11. A partir de la información que se disponia sobre la EHPM 1998, se ajustó el ingreso para cada decil en relación al tamaño promedio del hogar, con el fin de hacer lo más comparable que fuera posible el índice de Gini de 1998 con los resultados obtenidos por los organismos internacionales.

12. Cifras oficiales de la EHPM de 1998.

13. Datt y Ravallion, "Growth and Redistribution Components of Changes in Poverty Measure: Descomposition with Application to Brazil and India in the 1980", Living standards measurement study, working paper, 83, World Bank, 1991.

14. Los cálculos realizados no incluyen los efectos del gasto social existente.

15. CEPAL, Panorama social de América Latina 1998.

16. Moreno Raúl, "La reforma fiscal en El Salvador: Una exigencia impostergable", Serie de Alternativas para el Desarrollo, 58, FUNDE, p. 4.

17. El 8 por ciento restante se destina al pago de la deuda pública.

18. CEPAL, La brecha de la equidad, 1997.

19. CEPAL, Panorama social de América Latina 1998.

20. Banco Interamericano de Desarrollo, “Estrategia para reducir la pobreza”, p. 8.

21. Ídem.

22. FUSADES, Crecimiento con participación: una estrategia de desarrollo para el siglo XXI, abril, 1997.

23. Libro Blanco de la microcmpresa, El Salvador, 1997.

24. Microempresas de subsistencia: son aquellas que tienen tan baja productividad que sólo persiguen la generación de ingresos con propósitos de consumo inmediato. Se ubican en este segmento todas aquellas microempresas, cuyas ventas mensuales son menores o iguales a 15, 000 colones.

25. Microempresas de acumulación simple: son aquellas en las que los recursos productivos de la microempresa generan ingresos que cubren los costos de su actividad, aunque sin alcanzar excedentes suficientes que permitan la inversión en crecimiento. 
Se ubican en este grupo aquellas microemprèsas cuyas ventas mensuales fluctúan entre 15,0001 y 30,000 colones.

26. Idem., p. 31.

27. CEPAL, "Uso productivo de las remesas en El Salvador, Guatemala y Nicaragua", LC/MEX. 622, septiembre, 1998.

Digitalizado por Biblioteca "P. Florentino Idoate, S.J." Universidad Centroamericana José Simeón Cañas 